\title{
Evaluación de impactos ambientales y sociales del negocio de banca comercial en Europa durante el periodo 2006-2010
}

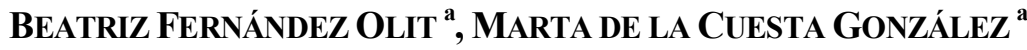 \\ a Universidad Nacional de Educación a Distancia (UNED), Facultad de CC.EE., Paseo Senda del \\ Rey, 11,28040 Madrid,España.E-mail: beaolit@gmail.com, mcuesta@cee.uned.es
}

\begin{abstract}
RESUMEN
El presente artículo analiza las responsabilidades técnicas o financieras de la banca, así como su responsabilidad social en su ámbito de negocio, estableciendo los vínculos y relaciones entre ambas. Los sistemas de evaluación y reporting en relación a la RSC externa o comercial muestran una insuficiente capacidad de integrar y valorar los impactos sociales y ambientales surgidos durante el primer periodo de crisis financiera mundial del siglo XXI. Así, tras la propuesta de un modelo revisado y completo de monitoreo, se experimenta su aplicación sobre las bases de datos de EIRIS y Asset4 ESG durante el periodo 2006-2010, obteniendo sendos índices de responsabilidad social comercial o externa de la banca europea. La cobertura de ambas bases de datos sobre el modelo es limitada, pero el análisis descriptivo de los resultados permite observar diferencias entre el tipo de negocio bancario que se desarrolla (de base, vinculado a la intermediación bancaria/ diversificado, con mayor protagonismo de las actividades de inversión) y su grado de RSC comercial, cuestionando la sostenibilidad social y ambiental del modelo de gran banca universal.
\end{abstract}

Palabras clave: Sector financiero, banca, RSC externa, crisis, medio ambiente, derechos humanos.

\section{Assessment of Social and Environmental Impacts Originated in Europe during the Period 2006-2010 by Banking Activities}

\begin{abstract}
This article analyses the technical and financial responsibilities of the banking sector, and reflects on their relation with the definition of social corporate responsibility applied exclusively to commercial banking activities. Mainstream assessment and reporting systems regarding external or commercial CSR show an insufficient capacity to integrate and evaluate the social and environmental impacts originated during the recent financial crisis. Therefore, after constructing a revised and completed assessment model, it has been applied to two different sustainability databases for the period 2006-2010. As a result, we have obtained both indexes of European banks regarding their external CSR performance. Despite obtaining a limited jointly coverage of total model by both databases, the descriptive analysis of results shows differences between the general characteristics of entities (size and banking specialization) and their external CSR rating. Thus, smaller banks and mainly oriented to financial intermediation show better performance than investment and large, universal banks, questioning the social and environmental sustainability of such model of banking.
\end{abstract}

Keywords: Financial Sector, Banks, External CSR, Environment, Human Rights.

Clasificación JEL: O16

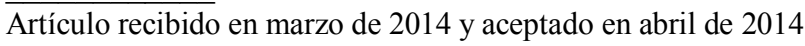

Artículo disponible en versión electrónica en la página www.revista-eea.net, ref. ə-32212 


\section{RESPONSABILIDAD EN EL EJERCICIO DE LA INTERMEDIACIÓN BANCARIA Y FINANCIERA}

El sector financiero, y concretamente el bancario, es considerado uno de los principales motores de la economía puesto que es el principal responsable de la redistribución de los recursos financieros. Existen unas responsabilidades técnicas o financieras que se le exigen al sector para garantizar el correcto funcionamiento del sistema financiero de una sociedad o país. Y en el caso de que estas responsabilidades se descuiden o ignoren pueden provocarse situaciones de crisis, que generalmente afectan al conjunto de la economía. Asimismo, ha de tenerse en cuenta la función selectiva que ejerce el sector financiero a la hora de 'premiar' con financiación a determinadas empresas o proyectos, frente a aquellos que no consiguen atraer el crédito o la inversión. Este hecho tiene importantes repercusiones en términos de sostenibilidad, puesto que la redistribución de recursos financieros puede condicionar el desarrollo de una economía más o menos respetuosa con el medio ambiente y las personas. El presente artículo analiza ambos tipos de responsabilidades, concentrándose en el estudio de los sistemas de monitoreo de la responsabilidad social del negocio bancario, y en su capacidad de integrar y evaluar los impactos sociales y ambientales surgidos durante el primer periodo de crisis financiera mundial del siglo XXI. Finalmente y tras la propuesta de un modelo de evaluación, se experimenta su aplicación sobre dos bases de datos obteniendo sendos índices de responsabilidad social comercial o externa de la banca europea.

\subsection{La relación entre la responsabilidad social y ambiental de las entidades financieras y sus responsabilidades primarias}

Numerosos autores plantean las responsabilidades $\mathrm{ASG}^{1}$ del sector financiero como derivadas de las responsabilidades primarias o generales del sector. De la Cuesta et al. (2006) identifican éstas como: (i) la intermediación entre unidades económicas con exceso y con déficit de recursos financieros; (ii) la adaptación de plazos, desde la captación de ahorros a corto plazo, al préstamo de largo plazo; (iii) la redistribución espacial del dinero [...]; y (iv) la evaluación de riesgos, generando información valiosa respecto a la rentabilidad y riesgo de las operaciones bancarias e inversiones. Esta última función es, en su opinión, la más importante a la hora de definir la responsabilidad social, ambiental y económica del negocio bancario: la evaluación del binomio rentabilidad-riesgo puede ampliarse a términos sociales y ambientales, lo que permitiría asignar un coste más realista a cada operación (aumentando o disminuyendo el tipo de interés a aplicar, o rechazando incluso las excesivamente arriesgadas).

\footnotetext{
${ }^{1}$ Ambientales, sociales y de gobierno corporativo. Adaptación al español del acrónimo inglés ESG (Environmental, Social and Governance).
} 
A su vez, Prior y Argandoña (2009) definen una serie de responsabilidades técnico-financieras de las entidades bancarias: (i) Transformar la madurez de activos y obligaciones; (ii) generar liquidez para que los ahorradores puedan recuperar rápidamente y a bajo coste sus fondos; (iii) reducir y redistribuir el riesgo de los ahorradores; (iv) ofrecer bajos costes transaccionales; (v) crear un eficiente sistema de pagos; (vi) proveer de servicios de asesoramiento y de gestión de activos; (vii) y como consecuencia de lo anterior, contribuir al crecimiento económico, a la disminución de la pobreza y al bienestar de la sociedad. Consideran que además cabe atribuirles responsabilidades morales y sociales.

Del cumplimiento con estas responsabilidades técnicas depende en gran medida la generación de un impacto social (y en el caso de la gestión de riesgos, también ambiental) positivo o negativo: la oferta de bajos costes transaccionales y la canalización de crédito hacia zonas rurales o deprimidas favorecen la inclusión financiera y social; la errónea gestión de la transformación de plazos y la consecuente reducción de liquidez, impide a personas y empresas acceder a sus activos monetarios, generando graves consecuencias económicas y sociales como las vividas en los denominados 'corralitos'. La banca ha de contar con que de la realización eficaz y eficiente de su función depende, no sólo la salud del sector financiero, sino la de toda la economía de un país o región, debido al papel de 'motor económico' que se le confiere. Los impactos económicos, bien sean positivos o negativos, tienen su traducción simultánea en impactos sociales. En este artículo se analizan diferentes tipos de impactos sociales y ambientales de la banca en la última década, desde la perspectiva de su ámbito de negocio, cuyos orígenes están relacionados con las responsabilidades consideradas primarias, las meramente técnicas o financieras ${ }^{2}$. No obstante, este tipo de impactos son frecuentemente definidos, enmarcados y gestionados desde un enfoque accesorio de responsabilidad social corporativa (RSC) o de reputación corporativa, sin establecer conexiones sólidas con el propio modelo de negocio.

Según de la Cuesta et al. (2006) la incorporación de la RSC en el sector bancario abarca dos dimensiones: las operaciones internas (responsabilidad social interna); y la intermediación financiera o bancaria junto con la gestión de activos (responsabilidad social externa o comercial). El presente trabajo se centra en esta segunda dimensión, que según las autoras citadas incluye la consideración de criterios sociales y ambientales en el diseño de productos, en la política de crédito de la entidad, etc. No obstante, algunas políticas como por ejemplo las que ofrecen condiciones ventajosas a determinados colectivos para evitar la exclusión social, podrían entenderse bien como RSC interna, bien como RSC externa o comercial. La aplicación de criterios de sostenibilidad para la concesión de financiación a grandes proyectos (project finance) podría a su vez rela-

\footnotetext{
${ }^{2}$ No se estudiarán los impactos relacionados con el gobierno corporativo por estar directamente asociado a la dimensión interna o institucional, que no es objeto del presente análisis.
} 
cionarse con la gestión de riesgos, incluidos los de reputación, así como con la política de rentabilidad (se requiere un ajuste en el margen operativo por el aumento de los costes de evaluación). Respecto a la integración de la RSC externa, de la Cuesta et al. (2006) consideran que habría sido puesta en marcha por muy pocas entidades financieras, fundamentalmente aquellas calificadas como banca ética.

Dentro de la RSC externa pueden identificarse tres grandes áreas de desarrollo (Schmid-Schönbein et al. 2002):

\subsubsection{La aplicación de criterios de sostenibilidad a los grandes proyectos de financiación bancaria}

Puede afirmarse que el principal avance en este sentido ha consistido en la progresiva difusión y adhesión a los Principios de Ecuador $^{3}$ por parte de la banca convencional. La firma de dicho compromiso obliga a la evaluación de los grandes proyectos de inversión bajo criterios de riesgo social, ambiental y de vulneración de los derechos humanos, previamente a la concesión de crédito. Asimismo, los bancos suscriptores han de emitir un informe anual que indique el número de transacciones evaluadas, su categorización y decisión sobre la financiación, así como del seguimiento de los proyectos.

\subsubsection{La aplicación de criterios de sostenibilidad a la gestión de activos}

La inversión socialmente responsable es considerada como una de las principales palancas para que las empresas de cualquier sector asuman criterios de sostenibilidad (Fernández Olit, 2008), por lo que podría considerarse la existencia de cierta responsabilidad subsidiaria por parte del sector financiero con respecto a las actuaciones ambientales y sociales de las empresas en las que invierte. Pero, como ya planteaban Dembinski et al. (2003):

i) Las empresas están expuestas a un accionariado que cada vez busca resultado en plazos cada vez más cortos, de forma especulativa y migrante, en vez de especializarse en el apoyo a un determinado sector industrial, impidiendo el desarrollo de objetivos de sostenibilidad. Así, la inversión a corto plazo puede estar contraviniendo los principios éticos o de RSC en los que se fundamenta el inversor socialmente responsable.

ii) La aplicación de criterios éticos o de responsabilidad social en la gestión de activos implica un coste mayor de recursos por la necesidad de proveerse de información desde las agencias de rating en sostenibilidad, y por el desarrollo de metodologías innovadoras.

\footnotetext{
${ }^{3}$ Los Principios de Ecuador fueron promovidos por la Corporación Financiera Internacional y el Banco Mundial y lanzados en junio de 2003. La lista de firmantes en marzo de 2014 ascendía a 79 entidades internacionales, entre las cuales se cuentan 5 bancos españoles.
} 


\subsubsection{Las actividades de banca minorista y relaciones con clientes}

Pérez-Ruiz y Rodríguez-del Bosque (2012) destacan la orientación y compromiso con el cliente como punto fuerte de las políticas de RSC de los bancos. Definen como actividades más relevantes en RSC comercial para el grupo de interés 'clientes':

- El establecimiento de procedimientos para responder a todas las quejas de los consumidores.

- Comportamiento honesto con los clientes.

- La oferta de información completa por parte de los empleados a los consumidores sobre los productos.

- Utilización de la satisfacción del consumidor como un indicador para mejorar la comercialización del servicio.

- Esfuerzo por conocer al consumidor y sus necesidades.

La responsabilidad comercial hacia los clientes entra en conflicto con el excesivo celo en la maximización de beneficios para los accionistas de las entidades bancarias: éste es señalado como uno de los factores causantes de la crisis financiera, y dicho enfoque liberal del modelo bancario es percibido como un riesgo y una merma de atención hacia los clientes. La obsesión por la maximización del $\mathrm{RoE}^{4}$ ha repercutido negativamente en los clientes a través de, por ejemplo, la venta de productos inadecuados.

\subsection{Modelos habituales para la evaluación del sector financiero en términos de RSC externa}

En los intentos académicos de evaluación de la RSC de la banca caben diferentes enfoques:

i) El enfoque descriptivo y sin intentos de cuantificación del valor de la RSC de las entidades bancarias particulares, como la identificación detallada de impactos sociales y ambientales de Dowell-Jones y Kinley (2011), en la que sí se valora el volumen de pobreza generado a raíz de la crisis motivada por el sector financiero internacional, o el análisis de casos de estudio de Humphreys y Brown (2008).

ii) La construcción de modelos para la asignación de un valor o índice de responsabilidad social a cada entidad bancaria, sin poner en relación dicha valoración con sus resultados financieros, como proponen de la Cuesta et al. (2006) con la intención de determinar la contribución social del negocio comercial de la banca española.

\footnotetext{
${ }^{4}$ Return on Equity.
} 
iii) Los modelos que contrastan la medición cuantitativa de la RSC con diversos indicadores financieros. Aquí se utilizan dimensiones financieras de tipo descriptivo como las que plantea Scholtens (2009), que concluye con una relación positiva entre el comportamiento socialmente responsable y el tamaño de la entidad, así como con la calidad del balance. $\mathrm{O}$ bien, se contrastan los resultados financieros como en el estudio realizado por Wu y Shen (2013) que demuestra una relación positiva entre la aplicación de RSC estratégica y una mejor performance financiera, medida

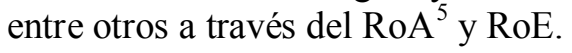

No obstante, la mayoría de los trabajos mencionados no reparan en diferenciar la RSC interna y la externa, por lo que existe una alta heterogeneidad en los aspectos medidos y la comparativa entre los diferentes modelos pierde sentido. Es así especialmente cuando se miden aspectos vinculados a la RSC pero con motivaciones muy distintas, como la aplicación de criterios de gobierno corporativo por impulso de la regulación, o el desarrollo de inversión socialmente responsable como respuesta a una demanda del mercado. Por ello, vamos a remitirnos directamente al análisis de las propuestas explícitas para el reporting en RSC y el rating de sostenibilidad de diferentes instituciones especializadas, aislando aquellos aspectos que refieren a la responsabilidad comercial o externa.

Social Performance Indicators for the Financial Industry (SPI Finance 2002), consistió en un proyecto de definición de indicadores en sostenibilidad y RSC para la industria financiera que, aunque no fue excesivamente utilizado por la industria, culminó en la edición del suplemento sectorial para sector financiero de la Global Reporting Initiative (GRI) ${ }^{6}$. En la Tabla 4 aparecen seleccionados aquellos indicadores GRI que tienen una componente de RSC comercial, enlazados con los correspondientes del SPI Finance 2002 (Tabla 1).

Tabla 1

Indicadores SPI Finance 2002 relacionados con la actividad comercial

\begin{tabular}{|c|c|c|c|c|c|c|c|c|}
\hline \multicolumn{3}{|c|}{ Retail Banking } & \multicolumn{3}{|c|}{ Investment Banking } & \multicolumn{3}{|c|}{ Asset Management } \\
\hline $\begin{array}{l}\text { RB 1: } \\
\text { Retail Banking } \\
\text { Policy (socially } \\
\text { relevant } \\
\text { elements) }\end{array}$ & $\begin{array}{l}\text { RB 2: } \\
\text { Lending } \\
\text { Profile }\end{array}$ & \begin{tabular}{|l} 
RB 3: \\
Lending \\
with High \\
Social \\
Benefit
\end{tabular} & \begin{tabular}{|l|} 
IB 1: \\
Investment \\
Banking Policy \\
(socially \\
relevant \\
elements)
\end{tabular} & $\begin{array}{l}\text { IB 2: } \\
\text { Customer } \\
\text { Profile: } \\
\text { Global } \\
\text { Transaction } \\
\text { Structure }\end{array}$ & $\begin{array}{l}\text { IB 3: } \\
\text { Transactions } \\
\text { with High } \\
\text { Social Benefit }\end{array}$ & \begin{tabular}{|l|} 
AM 1: \\
Asset \\
Management \\
Policy (socially \\
relevant \\
elements)
\end{tabular} & $\mid \begin{array}{l}\text { AM 2: } \\
\text { Assets under } \\
\text { Management } \\
\text { with High } \\
\text { Social Benefit }\end{array}$ & $\begin{array}{l}\text { AM 3: } \\
\text { SRI Oriented } \\
\text { Share-holder } \\
\text { Activity }\end{array}$ \\
\hline
\end{tabular}

Fuente: SPI Finance 2002.

Si observamos la definición de los principales impactos sociales y ambientales del negocio bancario que proponen las agencias de calificación o rating en

\footnotetext{
${ }^{5}$ Return on Assets.

${ }^{6}$ Global Reporting Initiative, Guía para la elaboración de Memorias de Sostenibilidad y Suplemento Sectorial para Servicios Financieros, en su versión G3.
} 


\section{sostenibilidad, en buena parte inspirada y trabajada conjuntamente con GRI, identificamos ${ }^{7}$ :}

\section{Tabla 2}

\section{Principales impactos sociales y ambientales del negocio bancario según las agencias de calificación social}

\begin{tabular}{|c|c|}
\hline $\begin{array}{l}\text { Satisfacción del cliente y responsabilidad del } \\
\text { producto: el negocio de la banca a particulares se } \\
\text { basa en la confianza y la adecuación del producto } \\
\text { a las necesidades del cliente. }\end{array}$ & $\begin{array}{l}\text { - Resultados y tendencias de la evaluación interna de } \\
\text { satisfacción del cliente. } \\
\text { - Resultados y tendencias sobre reclamaciones de clien- } \\
\text { tes, publicada por la autoridad competente. } \\
\text { - Políticas y sistemas de gestión de calidad y responsabili- } \\
\text { dad del producto (impacto en la comunidad, etc.) } \\
\text { - Procesos de investigación o multas por comportamien- } \\
\text { tos anti-competencia o fijación de precios. }\end{array}$ \\
\hline $\begin{array}{l}\text { Evaluación ambiental de la concesión de crédito: } \\
\text { en algunos países, como EE.UU., la banca puede } \\
\text { ser responsable subsidiaria del daño ambiental } \\
\text { causado por una empresa a la que financia. }\end{array}$ & $\begin{array}{l}\text { - Evaluación de riesgos ambientales en los procesos de } \\
\text { concesión del crédito o de gestión de activos. } \\
\text { - Política de desarrollo de productos y volumen de crédito } \\
\text { dedicado a la innovación ambiental }\end{array}$ \\
\hline $\begin{array}{l}\text { Evaluación de impacto del 'project finance' (finan- } \\
\text { ciación de grandes proyectos) en línea con los } \\
\text { Principios de Ecuador, o similares. }\end{array}$ & $\begin{array}{l}\text { - Política del banco respecto de la financiación de grandes } \\
\text { proyectos. } \\
\text { - Tipo de evaluación social y ambiental que se realiza. } \\
\text { - Suma total y porcentaje de financiación evaluado bajo } \\
\text { criterios tipo Principios de Ecuador. }\end{array}$ \\
\hline $\begin{array}{l}\text { Política de Inversión Socialmente Responsable: } \\
\text { bien para la oferta de servicios de gestión de } \\
\text { activos, o bien para la propia selección de inver- } \\
\text { siones por parte de la compañía. }\end{array}$ & $\begin{array}{l}\text { - Ofrece productos ISR } \\
\text { - Es sencillo para el cliente aplicar criterios de sostenibili- } \\
\text { dad y responsabilidad social a sus inversiones }\end{array}$ \\
\hline $\begin{array}{l}\text { Inclusión financiera: referente a la provisión de } \\
\text { productos de intermediación bancaria para todos } \\
\text { los ciudadanos. La banca utiliza mayoritariamente } \\
\text { activos públicos (entendidos frente a los recursos } \\
\text { privados de capital) y asume responsabilidades } \\
\text { de servicio básico. }\end{array}$ & $\begin{array}{l}\text { - Política del banco respecto a las personas con menores } \\
\text { ingresos y a las pymes } \\
\text { - Dispone el banco de productos especialmente diseñados } \\
\text { para estos grupos } \\
\text { - Controversias por cierre de sucursales, abandono de } \\
\text { zonas rurales, etc. }\end{array}$ \\
\hline $\begin{array}{l}\text { Impacto internacional: el impago de deuda por } \\
\text { parte de países pobres se convierte en una } \\
\text { cuestión política y ética. Asimismo sucede con las } \\
\text { operaciones monetarias. }\end{array}$ & $\begin{array}{l}\text { - Grado de exposición del banco a la deuda de los países } \\
\text { pobres } \\
\text { - Política con respecto a dicha deuda y respecto al im- } \\
\text { pago. }\end{array}$ \\
\hline $\begin{array}{l}\text { Blanqueo de capitales: aspecto ampliamente } \\
\text { regulado a nivel internacional, aunque el cumpli- } \\
\text { miento para los bancos es complejo y costoso. }\end{array}$ & $\begin{array}{l}\text { - } N^{\circ} \text { de incumplimientos, sanciones, etc. que ha recibido la } \\
\text { entidad a este respecto. } \\
\text { - Calidad del sistema anti blanqueo de capitales del } \\
\text { banco, en relación con el resto del sector. }\end{array}$ \\
\hline
\end{tabular}

Fuente: EIRIS, Asset 4 y elaboración propia.

\footnotetext{
${ }^{7}$ Siguiendo principalmente las metodologías EIRIS y Asset4 de evaluación de riesgos del sector bancario.
} 


\section{PROPUESTA DE MODELO POST-CRISIS PARA LA EVALUACIÓN DE IMPACTOS AMBIENTALES Y SOCIALES DE LA ACTIVIDAD COMERCIAL BANCARIA}

\subsection{Un mapeo de impactos sociales y ambientales durante el periodo de crisis financiera}

A continuación se presenta una síntesis del mapeo basado en fuentes empíricas $^{8}$ de los principales impactos sociales y ambientales causados por el negocio comercial del sector bancario durante la última década, prestando especial atención al periodo de crisis y al entorno español (Fernández Olit et al., 2014) 9 . Se ha realizado teniendo presentes las responsabilidades primarias del sector financiero (Prior y Argandoña, 2009), así como los factores que aceleraron el crecimiento económico y financiero en los inicios del siglo XXI, que también propiciaron la crisis (Llewellyn, 2009).

\section{Tabla 3}

Mapa de impactos sociales y ambientales durante

el periodo de crisis financiera 2008-2012

\begin{tabular}{|c|c|}
\hline Impacto & Autores y fuentes de referencia \\
\hline $\begin{array}{l}\text { Sobreendeudamiento de familias y } \\
\text { empresas, particularmente pymes }\end{array}$ & $\begin{array}{l}\text { Babecký et al., } 2012 . \\
\text { Banco de España, } 2012 . \\
\text { Prior y Argandoña, } 2009 .\end{array}$ \\
\hline Exclusión financiera & $\begin{array}{l}\text { De Serres y Roux, } 2006 . \\
\text { Fernández Olit, } 2012 . \\
\text { Defensor del Pueblo, } 2012 .\end{array}$ \\
\hline Desahucios & $\begin{array}{l}\text { Defensor del Pueblo, } 2012 \\
\text { Dowell-Jones y Kinley, } 2011 . \\
\text { Colau y Alemany, } 2013 .\end{array}$ \\
\hline $\begin{array}{l}\text { Desaparición de empresas y empleo: } \\
\text { inclusión financiera de la pyme }\end{array}$ & $\begin{array}{l}\text { Banco de España, 2012(b). Realizado en conjunto con FMl, la } \\
\text { Comisión Europea, el Supervisor Bancario Europeo (EBA) y el Tesoro } \\
\text { Español. }\end{array}$ \\
\hline $\begin{array}{l}\text { Productos 'tóxicos' y pérdida de ahorro } \\
\text { de las familias }\end{array}$ & $\begin{array}{l}\text { INVERCO, } 2012 . \\
\text { Banco de España, 2012(a). } \\
\text { Comisión de Seguimiento de Instrumentos Híbridos de Capital y } \\
\text { Deuda Subordinada, } 2013 . \\
\text { Dowell-Jones y Kinley, } 2011 .\end{array}$ \\
\hline Blanqueo de capitales & $\begin{array}{l}\text { Cid Gómez, J.M. del, } 2009 . \\
\text { KPMG, } 2011 .\end{array}$ \\
\hline $\begin{array}{l}\text { Sector financiero y derechos humanos } \\
\text { globales }\end{array}$ & $\begin{array}{l}\text { Naciones Unidas, } 2011 . \\
\text { Dowell-Jones y Kinley, } 2011 .\end{array}$ \\
\hline Crisis alimentaria & $\begin{array}{l}\text { Henderson et al., } 2012 . \\
\text { Banco Mundial. Comunicado de prensa No:2011/333/PREM. } \\
\text { WASHINGTON D.C., } 15 \text { de febrero de } 2011 .\end{array}$ \\
\hline $\begin{array}{l}\text { Conflictos armados y armas } \\
\text { controvertidas }\end{array}$ & $\begin{array}{l}\text { Setem, } 2012 . \\
\text { Roos et al., } 2012 .\end{array}$ \\
\hline
\end{tabular}

${ }^{8}$ Se han revisado principalmente bases documentales de prensa general y económica, organizaciones sociales y organismos reguladores.

${ }^{9}$ Se puede consultar el detalle de la identificación de impactos en la citada publicación. 
Tabla 3 (continuación)

Mapa de impactos sociales y ambientales durante

el periodo de crisis financiera 2008-2012

\begin{tabular}{|l|l|}
\hline \multicolumn{1}{|c|}{ Impacto } & \multicolumn{1}{c|}{ Autores y fuentes de referencia } \\
\hline Operaciones con deuda pública & $\begin{array}{l}\text { Ellmers y Todoulos, 2013. } \\
\text { UNCTAD, 2012. }\end{array}$ \\
\hline $\begin{array}{l}\text { Cambio climático y reducción de la } \\
\text { emisión de gases de efecto } \\
\text { invernadero }\end{array}$ & $\begin{array}{l}\text { World Resources Institute y World Business Council for Sustainable } \\
\text { Development (2011). }\end{array}$ \\
\hline
\end{tabular}

Fuente: Elaboración propia.

\subsection{Una propuesta revisada de indicadores para la medición de impactos ambientales y sociales en el negocio bancario}

Teniendo en cuenta el mapeo de riesgos e impactos sociales y ambientales realizado en el epígrafe anterior, y la limitada cobertura de los mismos que se realiza por parte de los sistemas convencionales de evaluación de RSC, se ha definido un modelo revisado que permite medir todas las dimensiones de la RSC externa o comercial de la banca. Para ello, se han utilizado como base los indicadores propuestos por GRI específicamente para el sector financiero y en la propuesta previa de SPI Finance. Además, el modelo incluye otros indicadores aportados por las herramientas consultadas, y se completa con propuestas propias para cubrir aquellas 'lagunas' de riesgos.

\section{Tabla 4}

Propuesta revisada de indicadores para la medición de impactos ambientales y sociales en el negocio bancario

\begin{tabular}{|c|c|c|c|c|c|c|c|}
\hline & & & GRI & $\begin{array}{c}\text { Relación } \\
\text { SPI }\end{array}$ & $\begin{array}{l}\text { Agencias } \\
\text { rating } \\
\text { sostenib. }\end{array}$ & $\begin{array}{l}\text { Otros } \\
\text { estudios } \\
\text { de ref }{ }^{10}\end{array}$ & $\begin{array}{l}\text { Experiencia } \\
\text { empírica }=\text { mapeo } \\
\text { riesgos }\end{array}$ \\
\hline & \multirow{4}{*}{$\begin{array}{l}\text { Cartera de } \\
\text { productos }\end{array}$} & $\begin{array}{l}\text { Políticas con aspectos } \\
\text { medioambientales, sociales y de } \\
\text { DDHH específicos aplicadas a las } \\
\text { líneas de negocio: ahorro, préstamo } \\
\text { y gestión de activos. }\end{array}$ & FS1 & $\begin{array}{l}\text { RB1; } \\
\text { IB1; } \\
\text { AM1 }\end{array}$ & $\mathrm{E}, \mathrm{A} 4$ & & $\begin{array}{l}\text { Derechos humanos } \\
\text { globales } \\
\text { Impacto ambiental }\end{array}$ \\
\hline \multirow{3}{*}{ 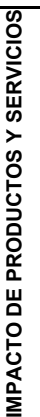 } & & \begin{tabular}{|l|} 
Procedimientos para la evaluación \\
y el control de riesgos sociales, de \\
DDHH y medioambientales en las \\
líneas de negocio.
\end{tabular} & FS2 & - & $\mathrm{E}, \mathrm{A} 4$ & & $\begin{array}{l}\text { Derechos humanos } \\
\text { globales } \\
\text { Impacto ambiental }\end{array}$ \\
\hline & & $\begin{array}{l}\text { Procesos para monitorizar la } \\
\text { implementación por parte de los } \\
\text { clientes de los requisitos sociales, } \\
\text { de derechos humanos (DDHH) y } \\
\text { medioambientales incluidos en } \\
\text { contratos o transacciones. }\end{array}$ & FS3 & - & A4 & & $\begin{array}{l}\text { Derechos humanos } \\
\text { globales } \\
\text { Impacto ambiental }\end{array}$ \\
\hline & & $\begin{array}{l}\text { Proceso(s) para mejorar la } \\
\text { competencia de los empleados } \\
\text { para implementar las políticas y } \\
\text { procedimientos medioambientales, } \\
\text { sociales y de DDHH aplicados a las } \\
\text { líneas de negocio. }\end{array}$ & FS4 & - & & & $\begin{array}{l}\text { Derechos humanos } \\
\text { globales } \\
\text { Impacto ambiental }\end{array}$ \\
\hline
\end{tabular}

${ }^{10}$ Véase los revisados en el apartado 2.1. 
Tabla 4 (continuación)

Propuesta revisada de indicadores para la medición de impactos ambientales y sociales en el negocio bancario

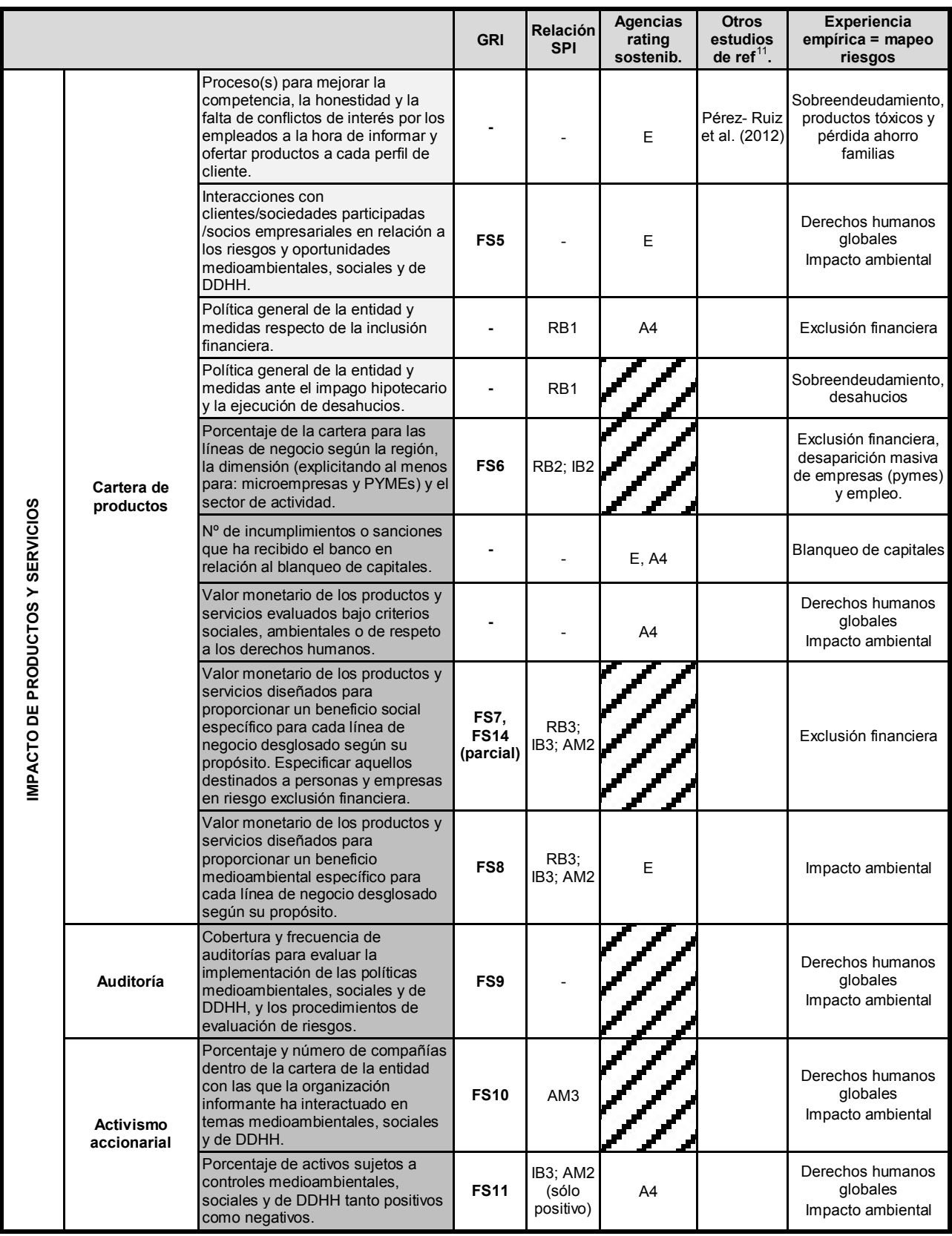

${ }^{11}$ Véase los revisados en el apartado 2.1. 
Tabla 4 (continuación)

Propuesta revisada de indicadores para la medición de impactos ambientales y sociales en el negocio bancario

\begin{tabular}{|c|c|c|c|c|c|c|c|}
\hline & & & GRI & $\begin{array}{c}\text { Relación } \\
\text { SPI }\end{array}$ & $\begin{array}{l}\text { Agencias } \\
\text { rating } \\
\text { sostenib. }\end{array}$ & $\begin{array}{l}\text { Otros } \\
\text { estudios } \\
\text { de ref }{ }^{12} \text {. }\end{array}$ & $\begin{array}{c}\text { Experiencia } \\
\text { empírica = mapeo } \\
\text { riesgos }\end{array}$ \\
\hline 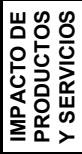 & $\begin{array}{l}\text { Activismo } \\
\text { accionarial }\end{array}$ & $\begin{array}{l}\text { Política(s) de voto en asuntos } \\
\text { medioambientales, sociales o de } \\
\text { DDHH en participaciones sobre las } \\
\text { cuales la organización informante } \\
\text { posee derecho de voto o } \\
\text { recomendación de voto. }\end{array}$ & FS12 & AM3 & & & $\begin{array}{l}\text { Derechos humanos } \\
\text { globales } \\
\text { Impacto ambiental }\end{array}$ \\
\hline \multirow{4}{*}{ 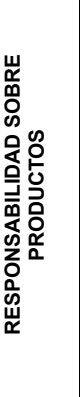 } & \multirow{2}{*}{$\begin{array}{l}\text { Etiquetado de } \\
\text { Productos y } \\
\text { Servicios }\end{array}$} & $\begin{array}{l}\text { Descripción de políticas para el } \\
\text { correcto diseño y oferta de servicios } \\
\text { y productos financieros. }\end{array}$ & FS15 & $\begin{array}{c}\text { RB1; } \\
\text { IB1; AM1 }\end{array}$ & & & $\begin{array}{l}\text { Productos tóxicos y } \\
\text { pérdida ahorro } \\
\text { familias }\end{array}$ \\
\hline & & $\begin{array}{l}\text { Iniciativas para mejorar la } \\
\text { alfabetización y educación } \\
\text { financiera (durante el proceso de } \\
\text { venta) según el tipo de beneficiario. }\end{array}$ & FS16 & RB1 & & & $\begin{array}{c}\text { Sobreendeudamiento, } \\
\text { productos tóxicos y } \\
\text { pérdida ahorro } \\
\text { familias }\end{array}$ \\
\hline & \multirow{2}{*}{$\begin{array}{l}\text { Satisfacción del } \\
\text { cliente }\end{array}$} & $\begin{array}{l}\text { Resultados y tendencias de la } \\
\text { evaluación interna de satisfacción } \\
\text { del cliente. }\end{array}$ & - & - & $\mathrm{E}, \mathrm{A} 4$ & & $\begin{array}{l}\text { Productos tóxicos y } \\
\text { pérdida ahorro } \\
\text { familias }\end{array}$ \\
\hline & & $\begin{array}{l}\text { Resultados y tendencias sobre } \\
\text { reclamaciones de clientes, } \\
\text { publicada por la autoridad } \\
\text { competente. }\end{array}$ & - & - & $\mathrm{E}, \mathrm{A} 4$ & & $\begin{array}{l}\text { Productos tóxicos y } \\
\text { pérdida ahorro } \\
\text { familias }\end{array}$ \\
\hline 号 & Comunidad & $\begin{array}{l}\text { Puntos de acceso por tipo en áreas } \\
\text { de escasa densidad de población o } \\
\text { desfavorecidas económicamente. }\end{array}$ & FS13 & RB1 & A4 & & Exclusión financiera \\
\hline \multirow{2}{*}{ 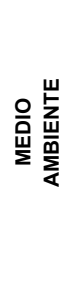 } & $\begin{array}{l}\text { Emisiones, } \\
\text { Vertidos } \\
\text { y Residuos }\end{array}$ & $\begin{array}{l}\text { Cómputo de 'emisiones financiadas' } \\
\text { de gases de efecto invernadero } \\
\text { (GHG) derivadas del préstamo } \\
\text { empresarial general, project } \\
\text { finance, y aseguramiento de deuda. }\end{array}$ & $\begin{array}{c}\text { EN16 } \\
\text { (parcial) }\end{array}$ & - & & & $\begin{array}{l}\text { Impacto ambiental. } \\
\text { Impacto cambio } \\
\text { climático }\end{array}$ \\
\hline & $\begin{array}{c}\text { Agua y } \\
\text { biodiversidad }\end{array}$ & $\begin{array}{l}\text { Cómputo de 'impactos financiados' } \\
\text { sobre los ecosistemas y recursos } \\
\text { acuíferos derivados del préstamo } \\
\text { empresarial general, project } \\
\text { finance, y aseguramiento de deuda. }\end{array}$ & - & - & & & Impacto ambiental \\
\hline \multirow{3}{*}{ 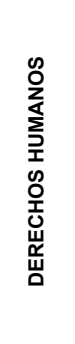 } & \multirow{3}{*}{$\begin{array}{l}\text { Prácticas de } \\
\text { Inversión y } \\
\text { Abastecimiento }\end{array}$} & $\begin{array}{l}\text { Política del banco frente a la deuda } \\
\text { de países pobres o en proceso de } \\
\text { empobrecimiento, incluida la } \\
\text { circunstancia de impago. }\end{array}$ & - & - & & & $\begin{array}{l}\text { Derechos humanos } \\
\text { globales. Operaciones } \\
\text { con deuda pública }\end{array}$ \\
\hline & & $\begin{array}{l}\text { Política del banco frente a la } \\
\text { inversión (propia y de terceros } \\
\text { mediante gestión de activos) en } \\
\text { materias primas y alimentos. }\end{array}$ & - & - & & & $\begin{array}{l}\text { Derechos humanos } \\
\text { globales. Crisis } \\
\text { alimentaria }\end{array}$ \\
\hline & & $\begin{array}{l}\text { Política frente a la financiación o } \\
\text { inversión de la entidad (propia y de } \\
\text { terceros mediante gestión de } \\
\text { activos) en armamento general y } \\
\text { controvertido. }\end{array}$ & - & - & & & $\begin{array}{l}\text { Derechos humanos } \\
\text { globales Conflictos } \\
\text { armados y armas } \\
\text { controvertidas }\end{array}$ \\
\hline
\end{tabular}

${ }^{12}$ Véase los revisados en el apartado 2.1. 
Tabla 4 (continuación)

Propuesta revisada de indicadores para la medición de impactos ambientales y sociales en el negocio bancario

\begin{tabular}{|c|c|c|c|c|c|c|c|}
\hline & & & GRI & $\begin{array}{c}\text { Relación } \\
\text { SPI }\end{array}$ & $\begin{array}{l}\text { Agencias } \\
\text { rating } \\
\text { sostenib. }\end{array}$ & $\begin{array}{l}\text { Otros } \\
\text { estudios } \\
\text { de ref }^{13} \text {. }\end{array}$ & $\begin{array}{c}\text { Experiencia } \\
\text { empírica }=\text { mapeo } \\
\text { riesgos }\end{array}$ \\
\hline \multirow{4}{*}{ 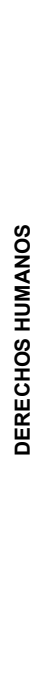 } & \multirow{4}{*}{$\begin{array}{l}\text { Prácticas de } \\
\text { Inversión y } \\
\text { Abastecimiento }\end{array}$} & \begin{tabular}{|l} 
Porcentaje y número total de \\
acuerdos de inversión significativos \\
que incluyan cláusulas de derechos \\
humanos o que hayan sido objeto \\
de análisis en materia de derechos \\
humanos: \\
Para los servicios financieros, "los \\
contratos de inversión" hacen \\
referencia a la gama de acuerdos \\
de financiación que incluyen \\
contratos bancarios estándar como \\
por ejemplo acuerdos de préstamos \\
y contratos de subvención así como \\
contratos de seguros [...] \\
\end{tabular} & HR1 & - & & & $\begin{array}{l}\text { Derechos humanos } \\
\text { globales }\end{array}$ \\
\hline & & $\begin{array}{l}\text { Grado de exposición del banco a la } \\
\text { deuda de países pobres o en } \\
\text { proceso de empobrecimiento. }\end{array}$ & - & - & & & $\begin{array}{l}\text { Derechos humanos } \\
\text { globales. Operaciones } \\
\text { con deuda pública }\end{array}$ \\
\hline & & $\begin{array}{l}\text { Volumen de financiación o inversión } \\
\text { de la entidad (propia y de terceros } \\
\text { mediante gestión de activos) en } \\
\text { materias primas y alimentos. }\end{array}$ & - & - & $E$ & & $\begin{array}{l}\text { Derechos humanos } \\
\text { globales. Crisis } \\
\text { alimentaria }\end{array}$ \\
\hline & & $\begin{array}{l}\text { Volumen de financiación o inversión } \\
\text { de la entidad (propia y de terceros } \\
\text { mediante gestión de activos) en } \\
\text { armamento general y controvertido. }\end{array}$ & - & - & $E$ & & $\begin{array}{l}\text { Derechos humanos } \\
\text { globales Conflictos } \\
\text { armados y armas } \\
\text { controvertidas }\end{array}$ \\
\hline
\end{tabular}

Marcadores de gestión

Marcadores de desempleo

$E=E I R I S ; A 4=$ Asset 4 ESG .

Fuente: Global Reporting Initiative, SPI Finance, y elaboración propia.

\section{APLICACIÓN EMPÍRICA DEL MODELO PROPUESTO PARA LA EVALUACIÓN DE LA RSC EXTERNA DEL SECTOR BANCARIO}

\subsection{Planteamiento metodológico: Bases de datos disponibles y contraste de cobertura del modelo}

El punto de referencia para el estudio de los impactos sociales y ambientales de la banca europea será el modelo de valoración propuesto en el apartado 2.2. Se ha elegido un análisis histórico del periodo 2006-2010, por dos razones: el estudio evolutivo desde un escenario boyante pre-crisis a un escenario de crisis madura en el sector financiero europeo, y la disponibilidad de datos homogéneos y sistematizados para el sector. El análisis requiere la utilización de bases de datos especializadas y reconocidas. Se han seleccionado la base de datos histórica (años 2006-2009; 50 bancos europeos) de la agencia de calificación

${ }^{13}$ Véase los revisados en el apartado 2.1. 
social EIRIS ${ }^{14}$ y la base de datos (años 2006-2010; 48 bancos europeos) de Asset4 ESG- Thomson Reuters ${ }^{15}$. En ambos casos se trata de bases de datos de empresas cotizadas, y se han seleccionados aquellas entidades categorizadas como banco en cualquiera de ambas herramientas.

EIRIS es una agencia de calificación social británica que dispone de una base de datos de análisis completo sobre 110 aspectos sociales, ambientales y de gobierno corporativo para 3.000 empresas, y de perfiles parciales para más de 7.000 empresas a nivel mundial. EIRIS contrasta los datos procedentes de la consulta y reporting empresarial con información extraída de prensa, organizaciones sociales, publicaciones sectoriales y de comercio, y datos de los organismos reguladores. EIRIS ofrece una valoración de cada indicador, modulada en varios grados de libertad (por ejemplo: avanzado, intermedio, limitado y no existente), que varían en función de la naturaleza del mismo. Es posible aplicar una valoración en escala a cada indicador.

Asset4 ESG dispone de información sobre 3.400 empresas a nivel global, obtenida desde fuentes públicas como la información corporativa. Se estructura en 250 aspectos sociales, ambientales, de gobierno corporativo y financieros, construidos sobre 750 indicadores básicos (data points), que son valorados en su mayoría de forma binaria $(0,1)$ en función de que la compañía cumpla o no con el indicador. Así, difiere de la metodología de EIRIS en la posibilidad de aplicar escalas a cada indicador.

En este punto encontramos la necesidad de contrastar qué cobertura del modelo teórico propuesto se puede lograr con las bases de datos elegidas. Según las Tablas 4 y 5 se ha estimado la cobertura que ambas bases de datos ofrecen respecto del modelo teórico de evaluación. Los marcadores o aspectos evaluados pueden reflejarse en varios indicadores.

Tabla 5

Estimación cobertura del modelo teórico de evaluación

\begin{tabular}{|l|l|l|}
\hline \multicolumn{1}{|c|}{ MODELO TEÓRICO } & \multicolumn{1}{|c|}{ EIRIS } & \multicolumn{1}{c|}{ ASSET 4 } \\
\hline 32 marcadores & $\begin{array}{l}27 \text { indicadores relevantes } \\
\text { Cobertura de 11 marcadores }\end{array}$ & $\begin{array}{l}\text { 21 indicadores relevantes } \\
\text { Cobertura de 11 marcadores }\end{array}$ \\
\hline$\%$ cobertura individual del modelo de evaluación & $34,38 \%$ & $34,38 \%$ \\
\hline$\%$ cobertura agregada del modelo de evaluación & $50,00 \%$ & \\
\hline
\end{tabular}

Fuente: Elaboración propia.

En conjunto, se puede afirmar que la información disponible en las bases de datos nos permite evaluar como máximo un 50\% del modelo teórico propuesto. En la Tabla 4 se señalan como celdas rayadas las 'lagunas de información', es

\footnotetext{
${ }^{14} \mathrm{http}: / /$ www.eiris.org/

${ }^{15} \mathrm{http}: / /$ thomsonreuters.com/esg-research-data/
} 
decir, impactos sociales y ambientales que aún no han sido implementados por estas agencias de información de sostenibilidad. Se estima que existen dos motivos principales para ello: reciente constatación de su trascendencia (a raíz de reacciones sociales o mediáticas) y/o falta de relevancia para las políticas de los inversores socialmente responsables, a quienes principalmente se dirigen estas herramientas.

\subsection{Análisis basado en el sistema de evaluación de EIRIS}

La información de la base de datos de EIRIS permite un análisis más amplio en relación con la responsabilidad social externa o comercial de la banca, pues ofrece indicadores en una serie mayor de marcadores del modelo propuesto. Encontramos indicadores de tipo ambiental que hacen referencia expresa al impacto del negocio de financiación, principalmente a través de los grandes proyectos o project finance. Por ejemplo, aunque la calificación del impacto ambiental es la misma para todo el sector de banca, asignándole un impacto medio, ello implica que EIRIS tiene en cuenta el potencial de riesgo indirecto a través de la financiación de terceros, pues la mera actividad corporativa de la banca sería considerada de bajo impacto. De la misma manera extrapolamos que, por ejemplo, la presencia y actividad en países con alto riesgo de vulneración de los derechos humanos implica un mayor riesgo de financiación de terceros que puedan estar involucrados en este tipo de conflictos. Para valorar el tipo de gestión que realizan las entidades bancarias respecto de los riesgos sociales y ambientales, se ha incidido en la calidad de los sistemas de gestión y de los resultados, y no tanto en la existencia de políticas. Se consigue una valoración equilibrada de riesgos/gestión de riesgos, gracias al juego de puntuaciones positivas y negativas. El enfoque que EIRIS nos ofrece respecto a la responsabilidad hacia el cliente y el producto, es más genérico y global que el que nos ofrece Asset4, por lo que se ha considerado la idoneidad de un análisis complementario con esta segunda base de datos.

El modelo de evaluación basado en información de EIRIS utiliza 27 indicadores clasificados en ocho áreas temáticas: 3 de tipo ambiental (impacto y gestión ambiental, project finance y sostenibilidad, cambio climático) desagregadas en 7 indicadores, 3 vinculadas a los derechos humanos (gestión DDHH, países en desarrollo, armamento) desagregadas en 12 indicadores; y 2 relacionadas con las relaciones comerciales (corrupción/soborno, consumidores) desagregadas en 8 indicadores. La contribución de cada área es equitativa para el cálculo final del índice. Las alteraciones cuantitativas en el resultado del índice por la desaparición o introducción de nuevos indicadores a lo largo del periodo analizado (como los indicadores de corrupción a partir de 2008), se han corregido mediante el cálculo de un índice en base 100, siendo éste el máximo resultado potencial y 0 el mínimo. La asignación de valores a la información de EIRIS varía 
entre indicadores (en base a las posibilidades de calificación de cada indicador) con una escala máxima de -3 a 3 , con el objetivo de aprovechar el mayor rango de matizaciones en el comportamiento empresarial que ofrece EIRIS (no disponible en Asset 4). En caso de existencia de sanciones (por ejemplo, vulneración de los DDHH) se valora dicotómicamente como -3 (existe sanción) o 0 (no existe sanción).

\section{Tabla 6}

Ranking histórico de entidades analizadas con información de EIRIS

\begin{tabular}{|c|c|c|c|c|c|c|c|c|c|}
\hline & \multicolumn{2}{|c|}{2009} & \multicolumn{2}{|c|}{2008} & \multicolumn{2}{|c|}{2007} & \multicolumn{2}{|c|}{2006} & \multirow{2}{*}{$\begin{array}{c}\begin{array}{c}\text { activos totales } \\
\text { (mill€) }^{16}\end{array} \\
30 / 07 / 2012\end{array}$} \\
\hline Entidad & $\begin{array}{c}\text { índice a } \\
100\end{array}$ & puesto & $\begin{array}{l}\text { índice a } \\
100\end{array}$ & puesto & $\begin{array}{c}\text { índice a } \\
100\end{array}$ & puesto & $\begin{array}{c}\text { índice a } \\
100\end{array}$ & puesto & \\
\hline Allied Irish Banks & 69 & $2^{\circ}$ & 69 & $2^{\circ}$ & 73 & $2^{\circ}$ & 69 & $4^{\circ}$ & $136.651(1)$ \\
\hline Alpha Bank & 67 & $11^{\circ}$ & 63 & $19^{\circ}$ & 67 & $12^{\circ}$ & 66 & $19^{\circ}$ & 53.773 \\
\hline Banca Carige & 64 & $19^{\circ}$ & 66 & $6^{\circ}$ & 67 & $13^{\circ}$ & 67 & $13^{\circ}$ & 44.860 \\
\hline $\begin{array}{l}\text { Banca Monte dei Paschi di } \\
\text { Siena }\end{array}$ & 71 & $1^{\circ}$ & 70 & $1^{\circ}$ & 63 & $23^{\circ}$ & 61 & $33^{\circ}$ & 240.702 \\
\hline Banca Popolare di Milano & 67 & $8^{\circ}$ & 67 & $5^{\circ}$ & 67 & $14^{\circ}$ & 67 & $14^{\circ}$ & 51.931 \\
\hline $\begin{array}{l}\text { Banco Bilbao Vizcaya } \\
\text { Argentaria }\end{array}$ & 67 & $10^{\circ}$ & 66 & $7^{\circ}$ & 62 & $27^{\circ}$ & 63 & $29^{\circ}$ & 637.784 \\
\hline Banco BPI & 58 & $37^{\circ}$ & 57 & $34^{\circ}$ & 62 & $29^{\circ}$ & 59 & $37^{\circ}$ & 42.956 \\
\hline Banco Comercial Portugues & 65 & $17^{\circ}$ & 65 & $14^{\circ}$ & 65 & $20^{\circ}$ & 65 & $23^{\circ}$ & 93.482 \\
\hline Banco de Valencia & 62 & $27^{\circ}$ & 62 & $25^{\circ}$ & 64 & $22^{\circ}$ & 64 & $26^{\circ}$ & $22.441(1)$ \\
\hline Banco Espanol de Credito & 68 & $5^{\circ}$ & 63 & $20^{\circ}$ & 69 & $6^{\circ}$ & 67 & $16^{\circ}$ & $108.818(1)$ \\
\hline Banco Espirito Santo & 52 & $45^{\circ}$ & 51 & $45^{\circ}$ & 58 & $37^{\circ}$ & 57 & $40^{\circ}$ & 80.237 \\
\hline Banco Popolare & 68 & $4^{\circ}$ & 66 & $8^{\circ}$ & 66 & $18^{\circ}$ & 66 & $20^{\circ}$ & 134.127 \\
\hline Banco Popular Espanol & 62 & $24^{\circ}$ & 53 & $43^{\circ}$ & 62 & $30^{\circ}$ & 62 & $31^{\circ}$ & 157.618 \\
\hline Banco Sabadell & 68 & $6^{\circ}$ & 68 & $3^{\circ}$ & 74 & $1^{\circ}$ & 75 & $1^{\circ}$ & 161.547 \\
\hline Banco Santander & 40 & $48^{\circ}$ & 44 & $49^{\circ}$ & 47 & $46^{\circ}$ & 47 & $46^{\circ}$ & 1.269 .628 \\
\hline Bank of Ireland & 62 & $23^{\circ}$ & 56 & $38^{\circ}$ & 58 & $38^{\circ}$ & 66 & $22^{\circ}$ & 148.146 \\
\hline Bankinter & 68 & $7^{\circ}$ & 68 & $4^{\circ}$ & 73 & $3^{\circ}$ & 69 & $5^{\circ}$ & 59.491 \\
\hline Barclays & 61 & $29^{\circ}$ & 66 & $9^{\circ}$ & 64 & $21^{\circ}$ & 63 & $27^{\circ}$ & 2.003 .078 \\
\hline BNP Paribas & 38 & $49^{\circ}$ & 37 & $50^{\circ}$ & 35 & $49^{\circ}$ & 34 & $48^{\circ}$ & 1.965 .283 \\
\hline Commerzbank & 51 & $46^{\circ}$ & 53 & $42^{\circ}$ & 54 & $42^{\circ}$ & 57 & $39^{\circ}$ & $844.103(2)$ \\
\hline Credit Agricole & 58 & $34^{\circ}$ & 60 & $28^{\circ}$ & 59 & $35^{\circ}$ & 65 & $24^{\circ}$ & 1.879 .536 \\
\hline Credit Suisse Group & 52 & $44^{\circ}$ & 53 & $44^{\circ}$ & 47 & $47^{\circ}$ & 53 & $44^{\circ}$ & 769.393 \\
\hline Danske Bank & 64 & $20^{\circ}$ & 63 & $21^{\circ}$ & 73 & $4^{\circ}$ & 69 & $6^{\circ}$ & 460.166 \\
\hline Deutsche Bank & 52 & $42^{\circ}$ & 51 & $46^{\circ}$ & 60 & $33^{\circ}$ & 61 & $34^{\circ}$ & 2.164 .103 \\
\hline Deutsche Postbank & 69 & $3^{\circ}$ & 66 & $10^{\circ}$ & 68 & $9^{\circ}$ & 68 & $10^{\circ}$ & 191.982 \\
\hline Dexia & 62 & $25^{\circ}$ & 65 & $15^{\circ}$ & 68 & $10^{\circ}$ & 62 & $32^{\circ}$ & 412.759 \\
\hline DnB NOR & 65 & $18^{\circ}$ & 65 & $16^{\circ}$ & 63 & $24^{\circ}$ & 69 & $7^{\circ}$ & 286.587 \\
\hline EFG Eurobank Ergasias & 67 & $12^{\circ}$ & 65 & $17^{\circ}$ & 71 & $5^{\circ}$ & 73 & $2^{\circ}$ & 76.822 \\
\hline EFG International & 56 & $39^{\circ}$ & 57 & $35^{\circ}$ & - & - & - & - & 19.667 \\
\hline Erste Group Bank & 67 & $13^{\circ}$ & 63 & $22^{\circ}$ & 69 & $7^{\circ}$ & 69 & $8^{\circ}$ & 210.006 \\
\hline Fortis & - & - & 56 & $39^{\circ}$ & 54 & $43^{\circ}$ & 53 & $43^{\circ}$ & $228.527(3)$ \\
\hline HSBC Holdings & 58 & $35^{\circ}$ & 58 & $33^{\circ}$ & 63 & $26^{\circ}$ & 63 & $30^{\circ}$ & 2.077 .842 \\
\hline Intesa-Sanpaolo & 57 & $38^{\circ}$ & 56 & $37^{\circ}$ & 44 & $48^{\circ}$ & 45 & $47^{\circ}$ & $673.472(4)$ \\
\hline KBC Groupe & 62 & $26^{\circ}$ & 66 & $11^{\circ}$ & 63 & $25^{\circ}$ & 60 & $35^{\circ}$ & 285.382 \\
\hline Lloyds Banking Group & 55 & $41^{\circ}$ & 54 & $41^{\circ}$ & 53 & $44^{\circ}$ & 64 & $25^{\circ}$ & 1.243 .493 \\
\hline Mediobanca & 56 & $40^{\circ}$ & 60 & $29^{\circ}$ & 58 & $39^{\circ}$ & 58 & $38^{\circ}$ & 75.392 \\
\hline
\end{tabular}

\footnotetext{
${ }^{16}$ Información extraída de la base de datos Bankscope y de las cuentas anuales de las entidades.
} 
Tabla 6 (continuación)

Ranking histórico de entidades analizadas con información de EIRIS

\begin{tabular}{|c|c|c|c|c|c|c|c|c|c|}
\hline \multirow[b]{2}{*}{ Entidad } & \multicolumn{2}{|c|}{2009} & \multicolumn{2}{|c|}{2008} & \multicolumn{2}{|c|}{2007} & \multicolumn{2}{|c|}{2006} & \multirow{2}{*}{$\begin{array}{c}\begin{array}{c}\text { activos totales } \\
\text { (mill€) }^{17}\end{array} \\
30 / 07 / 2012\end{array}$} \\
\hline & $\begin{array}{l}\text { indice a } \\
100\end{array}$ & puesto & $\begin{array}{l}\text { indice a } \\
100\end{array}$ & puesto & $\begin{array}{c}\text { indice a } \\
100\end{array}$ & puesto & $\begin{array}{c}\text { indice a } \\
100\end{array}$ & puesto & \\
\hline National Bank of Greece & 64 & $21^{\circ}$ & 62 & $26^{\circ}$ & 66 & $19^{\circ}$ & 68 & $21^{\circ}$ & 106.870 \\
\hline NATIXIS & 58 & $36^{\circ}$ & 51 & $47^{\circ}$ & 60 & $34^{\circ}$ & 66 & $11^{\circ}$ & $458.010(5)$ \\
\hline Nordea & 49 & $47^{\circ}$ & 49 & $48^{\circ}$ & 52 & $45^{\circ}$ & 69 & $9^{\circ}$ & 625.800 \\
\hline Piraeus Bank & 59 & $30^{\circ}$ & 57 & $36^{\circ}$ & 59 & $36^{\circ}$ & 56 & $41^{\circ}$ & 49.352 \\
\hline $\begin{array}{l}\text { Raiffeisen International Bank- } \\
\text { Holding }\end{array}$ & 59 & $33^{\circ}$ & 59 & $32^{\circ}$ & 69 & $8^{\circ}$ & 67 & $17^{\circ}$ & 146.985 \\
\hline $\begin{array}{l}\text { SEB - Skandinaviska Enskilda } \\
\text { Banken }\end{array}$ & 59 & $31^{\circ}$ & 62 & $27^{\circ}$ & 61 & $31^{\circ}$ & 67 & $18^{\circ}$ & 293.176 \\
\hline Societe Generale & 61 & $28^{\circ}$ & 59 & $30^{\circ}$ & 67 & $16^{\circ}$ & 72 & $3^{\circ}$ & 1.181.372 \\
\hline Standard Chartered & 65 & $16^{\circ}$ & 66 & $12^{\circ}$ & 62 & $28^{\circ}$ & 59 & $36^{\circ}$ & 487.080 \\
\hline Svenska Handelsbanken & 67 & $14^{\circ}$ & 65 & $18^{\circ}$ & 66 & $17^{\circ}$ & 68 & $12^{\circ}$ & 285.337 \\
\hline Swedbank & 67 & $15^{\circ}$ & 56 & $40^{\circ}$ & 57 & $40^{\circ}$ & 63 & $28^{\circ}$ & 220.700 \\
\hline $\begin{array}{l}\text { The Royal Bank of Scotland } \\
\text { Group }\end{array}$ & 52 & $43^{\circ}$ & 59 & $31^{\circ}$ & 57 & $41^{\circ}$ & 51 & $45^{\circ}$ & 1.930 .643 \\
\hline UBS & 59 & $32^{\circ}$ & 66 & $13^{\circ}$ & 68 & $11^{\circ}$ & - & - & 1.048 .216 \\
\hline UniCredit & 63 & $22^{\circ}$ & 62 & $24^{\circ}$ & 61 & $32^{\circ}$ & 56 & $42^{\circ}$ & 926.769 \\
\hline Unione di Banche Italiane & 67 & $9^{\circ}$ & 63 & $23^{\circ}$ & 67 & $15^{\circ}$ & 67 & $15^{\circ}$ & $129.800(1)$ \\
\hline correlación tamaño & $-0,5652$ & & $-0,3938$ & & $-0,4338$ & & $-0,4179$ & & \\
\hline Media geométrica sector & 60,29 & & 59,74 & & 61,35 & & 62,09 & & \\
\hline Media geom. española & 61,29 & & 59,89 & & 63,79 & & 63,18 & & \\
\hline & & & 49.35 & & maño mi & nimo & & & \\
\hline & & & 2.164 .10 & & maño me & ximo & & & \\
\hline & & & 544.03 & & amaño m & edio & & & \\
\hline & & & 234.61 & & mediar & & & & \\
\hline
\end{tabular}

* Información en fecha de (1) 30/12/2011, (2) 31/12/2009, (3) 30/06/2010, (4) 31/12/2012 y (5) 31/12/2010.

Fuente: Elaboración propia con información de EIRIS, Bankscope y cuentas anuales de las entidades.

En la Tabla 6 vemos cierta tendencia de las empresas en cuanto a mantenerse históricamente en un determinado sector del índice. Si analizamos las $10 \mathrm{em}-$ presas con menor puntuación, vemos que todas ellas han estado al menos durante tres ejercicios entre las 15 empresas con peor resultado (aproximadamente el tercio inferior de la clasificación), y entre la mitad inferior durante todo el periodo analizado. La ligera caída en el año 2008 corresponde en ambos casos a la introducción de criterios sobre corrupción y soborno.

Sin embargo, y aunque tampoco resulta concluyente, la relación entre los resultados del sistema EIRIS y el tamaño de las empresas, medido por sus activos totales, nos muestra una ligera correlación negativa que se acentúa en 2009. Ha de tenerse en cuenta que las entidades mayores y más internacionalizadas están expuestas a mayores riesgos y por tanto, a la generación de mayores impactos

\footnotetext{
${ }^{17}$ Información extraída de la base de datos Bankscope y de las cuentas anuales de las entidades.
} 
sociales y ambientales. El factor tamaño está además muy relacionado con el tipo de modelo bancario con el que se identifica la entidad. La banca con un origen y enfoque social (orientada al mercado minorista, con una menor diversificación de productos y activos, ligada al territorio y a la inclusión financiera, y representada principalmente por cajas de ahorro, cajas postales y cooperativas de crédito) está compuesta por entidades de menor tamaño relativo. La gran banca suele estar representada por entidades muy orientadas al mercado, con mayor peso de la actividad de inversión y de la banca corporativa, una mayor diversificación de activos, y mayor actividad internacional.

Se ha realizado un análisis comparativo entre los paneles de las 10 entidades con mayor y menor puntuación en 2009, observando algunas características financieras. Así, la banca europea líder en responsabilidad social comercial o externa está compuesta por entidades pequeñas, con orientación u origen preferente en un modelo de banca social (cajas de ahorro, banca cooperativa), con orientación al mercado minorista y a las actividades básicas de intermediación bancaria (productos de ahorro y crédito), con extensas redes de sucursales y un ratio elevado de empleados en función de su volumen de activos. La banca con peor comportamiento en responsabilidad social externa muestra un tamaño mayor, con presencia mayoritaria de grandes bancos, con actividades más diversificadas, definiéndose como banca de inversión o corporativa en varios casos, y con menor peso relativo de la actividad minorista fundamental de crédito y ahorro. Asimismo, demuestran menores ratios de sucursales y empleados en base a su volumen de activos.

En cuanto a la evolución de las empresas españolas (resaltadas en gris claro) se da un mejor comportamiento de su calificación media respecto del sector en Europa durante todo el periodo estudiado.

Se han marcado en gris oscuro las entidades bancarias que han sido recientemente multadas e investigadas por parte de la Comisión Europea a causa de la manipulación de los tipos de interés interbancario (líbor y euribor) entre 2005 y 2010. Teniendo en cuenta que estas malas prácticas anti-competencia, muy vinculadas con el negocio comercial, fueron llevadas a cabo durante el periodo analizado en la investigación, se ha considerado de interés observar la evolución de las entidades que las llevaron a cabo: Se puede destacar que, pese a la dispersión generalizada de la calificación de estas entidades entre el 2006 y 2008, en 2009 las siete entidades involucradas se posicionan entre la mitad más rezagada de la clasificación. Nótese que se refleja de nuevo una clara relación con su tamaño, pues todas las entidades pertenecen a la gran banca europea, que podríamos definir como la que maneja activos por valor de más de un billón de euros. 


\subsection{Análisis basado en el sistema de evaluación de Asset4}

Toda la serie histórica se ha calculado en base a 3 áreas o categorías, distribuidas en 21 indicadores que cubren 11 marcadores del modelo teórico de evaluación. Al igual que con EIRIS, la información de ASSET 4 aporta la posibilidad de medir -en algunos casos de forma incompleta o aproximada- un $34,38 \%$ de dicha propuesta. Las categorías e indicadores elegidos están directamente relacionados con el producto o cliente de las entidades bancarias (fidelización del cliente, innovación del producto, responsabilidad hacia el cliente y producto). La valoración posible tiene una base binaria $(1,0)$, dependiendo si se cumple la premisa o no. Los indicadores con sesgo negativo (incumplimientos, sanciones, etc.) se añaden al modelo como resta, en vez de suma. Para facilitar la comparabilidad también se ha desarrollado la equivalencia a un índice de base 100, donde ésta es la máxima puntuación potencial. El cálculo de índices para medir la responsabilidad social externa del sector bancario ha implicado durante el trabajo con ambas bases de datos, la selección de indicadores específicos, evitando en lo posible la introducción de indicadores con componente de RSC interna o corporativa. La utilización de índices prediseñados y propuestos por las entidades de calificación social ha quedado reducida al contraste recogido en la Tabla 7 respecto al índice sobre RSC general ESGC o Integrated Rating que elabora Asset4. EIRIS no propone ni publica ningún índice o ranking pre-elaborado.

Tabla 7

Ranking histórico de entidades analizadas con información de Asset4

\begin{tabular}{|c|c|c|c|c|c|c|c|c|c|c|}
\hline \multirow{2}{*}{ Entidad } & \multicolumn{2}{|c|}{$\begin{array}{c}\text { ÍNDICE BASE } \\
100\end{array}$} & \multicolumn{2}{|c|}{$\begin{array}{c}\text { ÍNDICE BASE } \\
100\end{array}$} & \multicolumn{2}{|c|}{$\begin{array}{c}\text { ÍNDICE BASE } \\
100\end{array}$} & \multicolumn{2}{|c|}{$\begin{array}{c}\text { ÍNDICE BASE } \\
100\end{array}$} & \multicolumn{2}{|c|}{$\begin{array}{c}\text { ÍNDICE BASE } \\
100\end{array}$} \\
\hline & 2010 & puesto & 2009 & puesto & 2008 & puesto & 2007 & puesto & 2006 & puesto \\
\hline Banco Popular Espanol SA & 87,9 & $1^{\circ}$ & 87,9 & $6^{\circ}$ & 78,2 & $13^{\circ}$ & 56,3 & $28^{\circ}$ & 37,3 & $25^{\circ}$ \\
\hline Intesa Sanpaolo SpA & 84,7 & $2^{\circ}$ & 74,0 & $23^{\circ}$ & 89,7 & $4^{\circ}$ & 86,5 & $2^{\circ}$ & 71,2 & $5^{\circ}$ \\
\hline Banco Comercial Portugues SA & 84,7 & $3^{\circ}$ & 88,9 & $4^{\circ}$ & 78,2 & $12^{\circ}$ & 78,2 & $5^{\circ}$ & 61,1 & $12^{\circ}$ \\
\hline Standard Chartered PLC & 81,7 & $4^{\circ}$ & 95,2 & $2^{\circ}$ & 92,1 & $3^{\circ}$ & 71,6 & $12^{\circ}$ & 67,5 & $8^{\circ}$ \\
\hline Alpha Bank S.A. & 81,3 & $5^{\circ}$ & 81,3 & $14^{\circ}$ & 42,5 & $41^{\circ}$ & 42,5 & $38^{\circ}$ & 26,2 & $40^{\circ}$ \\
\hline BNP Paribas SA & 80,0 & $6^{\circ}$ & 79,2 & $17^{\circ}$ & 73,6 & $16^{\circ}$ & 73,6 & $8^{\circ}$ & 61,5 & $11^{\circ}$ \\
\hline Barclays PLC & 77,6 & $7^{\circ}$ & 72,0 & $25^{\circ}$ & 67,5 & $27^{\circ}$ & 81,0 & $4^{\circ}$ & 81,0 & $2^{\circ}$ \\
\hline KBC Groep NV & 76,4 & $8^{\circ}$ & 90,3 & $3^{\circ}$ & 82,3 & $10^{\circ}$ & 62,9 & $19^{\circ}$ & 68,8 & $6^{\circ}$ \\
\hline Banca Monte dei Paschi di Siena SpA & 76,4 & $9^{\circ}$ & 84,7 & $10^{\circ}$ & 72,2 & $18^{\circ}$ & 56,3 & $25^{\circ}$ & 45,2 & $21^{\circ}$ \\
\hline Societe Generale SA & 73,4 & $10^{\circ}$ & 95,8 & $1^{\circ}$ & 95,8 & $1^{\circ}$ & 73,6 & $9^{\circ}$ & 58,7 & $15^{\circ}$ \\
\hline Commerzbank AG & 72,6 & $11^{\circ}$ & 64,3 & $32^{\circ}$ & 87,9 & $6^{\circ}$ & 59,1 & $23^{\circ}$ & 59,1 & $14^{\circ}$ \\
\hline Banco Bilbao Vizcaya Argentaria S.A. & 70,8 & $12^{\circ}$ & 84,7 & $11^{\circ}$ & 88,9 & $5^{\circ}$ & 76,4 & $7^{\circ}$ & 56,3 & $17^{\circ}$ \\
\hline Deutsche Postbank AG & 70,8 & $13^{\circ}$ & 80,6 & $16^{\circ}$ & 61,1 & $34^{\circ}$ & 53,2 & $32^{\circ}$ & 56,3 & $18^{\circ}$ \\
\hline DNB ASA & 70,8 & $14^{\circ}$ & 86,5 & $8^{\circ}$ & 56,9 & $35^{\circ}$ & 52,2 & $34^{\circ}$ & 39,7 & $24^{\circ}$ \\
\hline Credit Agricole SA & 68,8 & $15^{\circ}$ & 87,9 & $7^{\circ}$ & 82,3 & $9^{\circ}$ & 72,6 & $11^{\circ}$ & 82,3 & $1^{\circ}$ \\
\hline Royal Bank of Scotland Group plc & 68,8 & $16^{\circ}$ & 84,1 & $12^{\circ}$ & 68,8 & $24^{\circ}$ & 73,0 & $10^{\circ}$ & 71,6 & $4^{\circ}$ \\
\hline UBI Banca Scpa & 68,5 & $17^{\circ}$ & 76,8 & $18^{\circ}$ & 79,6 & $11^{\circ}$ & 66,1 & $15^{\circ}$ & 34,1 & $29^{\circ}$ \\
\hline Danske Bank A/S & 66,1 & $18^{\circ}$ & 81,0 & $15^{\circ}$ & 69,8 & $21^{\circ}$ & 61,9 & $20^{\circ}$ & 37,3 & $26^{\circ}$ \\
\hline
\end{tabular}


Tabla 7 (continuación)

Ranking histórico de entidades analizadas con información de Asset4

\begin{tabular}{|c|c|c|c|c|c|c|c|c|c|c|}
\hline \multirow[t]{2}{*}{ Entidad } & \multicolumn{2}{|c|}{$\begin{array}{c}\text { ÍNDICE BASE } \\
100\end{array}$} & \multicolumn{2}{|c|}{$\begin{array}{c}\text { ÍNDICE BASE } \\
100\end{array}$} & \multicolumn{2}{|c|}{$\begin{array}{c}\text { ÍNDICE BASE } \\
100\end{array}$} & \multicolumn{2}{|c|}{$\begin{array}{c}\text { ÍNDICE BASE } \\
100\end{array}$} & \multicolumn{2}{|c|}{$\begin{array}{c}\text { ÍNDICE BASE } \\
100\end{array}$} \\
\hline & 2010 & puesto & 2009 & puesto & 2008 & puesto & 2007 & puesto & 2006 & puesto \\
\hline National Bank of Greece & 66,1 & $19^{\circ}$ & 74,4 & $22^{\circ}$ & 67,5 & $28^{\circ}$ & 54,0 & $30^{\circ}$ & 20,6 & $46^{\circ}$ \\
\hline Banco Espirito Santo SA & 63,7 & $20^{\circ}$ & 88,9 & $5^{\circ}$ & 94,4 & $2^{\circ}$ & 56,3 & $27^{\circ}$ & 59,5 & $13^{\circ}$ \\
\hline Skandinaviska Enskilda Banken AB & 63,7 & $21^{\circ}$ & 84,1 & $13^{\circ}$ & 74,4 & $15^{\circ}$ & 60,5 & $21^{\circ}$ & 31,7 & $34^{\circ}$ \\
\hline Swedbank AB & 63,7 & $22^{\circ}$ & 55,0 & $35^{\circ}$ & 68,8 & $25^{\circ}$ & 55,0 & $29^{\circ}$ & 31,7 & $35^{\circ}$ \\
\hline Banco Espanol de Credito SA & 62,9 & $23^{\circ}$ & 58,7 & $34^{\circ}$ & 72,6 & $17^{\circ}$ & 56,3 & $26^{\circ}$ & 23,0 & $42^{\circ}$ \\
\hline Dexia SA & 60,5 & $26^{\circ}$ & 73,6 & $24^{\circ}$ & 69,8 & $22^{\circ}$ & 83,3 & $3^{\circ}$ & 75,4 & $3^{\circ}$ \\
\hline Bank of Ireland & 60,5 & $25^{\circ}$ & 63,7 & $33^{\circ}$ & 65,1 & $30^{\circ}$ & 59,5 & $22^{\circ}$ & 31,7 & $31^{\circ}$ \\
\hline Banco Santander, S.A. & 60,5 & $24^{\circ}$ & 76,8 & $19^{\circ}$ & 76,4 & $14^{\circ}$ & 66,7 & $14^{\circ}$ & 31,0 & $37^{\circ}$ \\
\hline UBS AG & 58,9 & $27^{\circ}$ & 72,0 & $26^{\circ}$ & 70,6 & $20^{\circ}$ & 63,3 & $18^{\circ}$ & 63,3 & $10^{\circ}$ \\
\hline Credit Suisse Group AG & 58,1 & $28^{\circ}$ & 71,2 & $27^{\circ}$ & 68,1 & $26^{\circ}$ & 68,1 & $13^{\circ}$ & 68,1 & $7^{\circ}$ \\
\hline Deutsche Bank AG & 58,1 & $29^{\circ}$ & 86,5 & $9^{\circ}$ & 83,3 & $7^{\circ}$ & 77,8 & $6^{\circ}$ & 64,3 & $9^{\circ}$ \\
\hline Nordea Bank AB & 57,3 & $30^{\circ}$ & 75,4 & $21^{\circ}$ & 69,8 & $23^{\circ}$ & 57,7 & $24^{\circ}$ & 57,7 & $16^{\circ}$ \\
\hline Raiffeisen Bank International AG & 57,3 & $31^{\circ}$ & 49,4 & $39^{\circ}$ & 49,4 & $36^{\circ}$ & 34,1 & $42^{\circ}$ & 23,0 & $43^{\circ}$ \\
\hline Svenska Handelsbanken AB & 54,0 & $32^{\circ}$ & 64,7 & $31^{\circ}$ & 64,7 & $31^{\circ}$ & 64,7 & $17^{\circ}$ & 37,3 & $28^{\circ}$ \\
\hline UniCredit SpA & 52,6 & $33^{\circ}$ & 76,4 & $20^{\circ}$ & 83,3 & $8^{\circ}$ & 65,7 & $16^{\circ}$ & 52,6 & $20^{\circ}$ \\
\hline Lloyds Banking Group PLC & 51,6 & $34^{\circ}$ & 67,1 & $29^{\circ}$ & 67,1 & $29^{\circ}$ & 53,2 & $33^{\circ}$ & 37,3 & $27^{\circ}$ \\
\hline Bankinter SA & 50,8 & $35^{\circ}$ & 53,2 & $36^{\circ}$ & 61,5 & $33^{\circ}$ & 53,6 & $31^{\circ}$ & 42,9 & $22^{\circ}$ \\
\hline Provident Financial plc & 50,8 & $37^{\circ}$ & 50,8 & $38^{\circ}$ & 48,4 & $37^{\circ}$ & 42,9 & $37^{\circ}$ & 31,7 & $33^{\circ}$ \\
\hline Natixis SA & 50,8 & $36^{\circ}$ & 71,2 & $28^{\circ}$ & 61,5 & $32^{\circ}$ & 47,6 & $35^{\circ}$ & 20,6 & $47^{\circ}$ \\
\hline HSBC Holdings plc & 44,6 & $38^{\circ}$ & 65,1 & $30^{\circ}$ & 70,6 & $19^{\circ}$ & 86,5 & $1^{\circ}$ & 56,3 & $19^{\circ}$ \\
\hline EFG Eurobank Ergasias S.A. & 43,8 & $39^{\circ}$ & 52,2 & $37^{\circ}$ & 34,1 & $43^{\circ}$ & 34,1 & $41^{\circ}$ & 28,6 & $38^{\circ}$ \\
\hline Allied Irish Banks, plc & 38,3 & $40^{\circ}$ & 43,5 & $40^{\circ}$ & 44,2 & $40^{\circ}$ & 44,2 & $36^{\circ}$ & 26,2 & $39^{\circ}$ \\
\hline Erste Group Bank AG & 36,5 & $42^{\circ}$ & 42,1 & $42^{\circ}$ & 47,6 & $38^{\circ}$ & 31,0 & $44^{\circ}$ & 31,7 & $32^{\circ}$ \\
\hline Banca Popolare di Milano & 36,5 & $41^{\circ}$ & 42,1 & $41^{\circ}$ & 42,1 & $42^{\circ}$ & 42,1 & $39^{\circ}$ & 31,0 & $36^{\circ}$ \\
\hline Banco BPI SA & 34,1 & $43^{\circ}$ & 34,1 & $44^{\circ}$ & 45,2 & $39^{\circ}$ & 39,7 & $40^{\circ}$ & 39,7 & $23^{\circ}$ \\
\hline Banco Popolare Societa Cooperativa & 34,1 & $44^{\circ}$ & 34,1 & $45^{\circ}$ & 26,2 & $45^{\circ}$ & 31,7 & $43^{\circ}$ & 26,2 & $41^{\circ}$ \\
\hline Banca Carige SpA & 31,7 & $45^{\circ}$ & 31,7 & $46^{\circ}$ & 26,2 & $44^{\circ}$ & 26,2 & $45^{\circ}$ & 31,7 & $30^{\circ}$ \\
\hline Mediobanca Group & 31,7 & $46^{\circ}$ & 26,2 & $48^{\circ}$ & 26,2 & $48^{\circ}$ & 26,2 & $48^{\circ}$ & 20,6 & $45^{\circ}$ \\
\hline EFG International AG & 26,2 & $47^{\circ}$ & 26,2 & $47^{\circ}$ & 26,2 & $46^{\circ}$ & 26,2 & $46^{\circ}$ & - & - \\
\hline Banco de Valencia SA & 26,2 & $48^{\circ}$ & 34,5 & $43^{\circ}$ & 26,2 & $47^{\circ}$ & 26,2 & $47^{\circ}$ & 20,6 & $44^{\circ}$ \\
\hline Media geométrica & 56,7 & & 64,0 & & 60,9 & & 54,1 & & 41,7 & \\
\hline Correlación con tamaño ( $n^{\circ}$ emplea.) & 0,2559 & & 0,3636 & & 0,4364 & & 0,6089 & & 0,4717 & \\
\hline Correlación índice ESGC $^{18}$ & 0,7828 & & 0,8656 & & 0,8759 & & 0,8709 & & 0,7937 & \\
\hline
\end{tabular}

Fuente: Elaboración propia con información de Asset4.

La Tabla 7 muestra los resultados del índice creado con información de Asset4, que permite examinar concretamente los aspectos de responsabilidad e innovación en los productos y la fidelización de clientes, puesto que los indicadores disponibles se concentran en pocos marcadores del modelo.

${ }^{18}$ El índice ESGC, también denominado 'Integrated Rating' es un rating calculado por Asset 4 para cada compañía en base a un modelo de valoración propio y equilibrado en cuanto a los pilares económico, ambiental, social y de gobierno corporativo. Incluye además el 100\% de la información disponible sobre controversias para cada empresa. El índice de correlación se calcula para cada año estudiado entre el rating obtenido por el índice ESGC y el obtenido por nuestro modelo. Para conocer más información sobre la construcción del índice ESGC de Asset4 puede consultarse Ribando y Bonne (2010), pág. 4. 
Su composición difiere mucho del índice creado bajo el sistema de evaluación de EIRIS. De hecho, el cálculo del coeficiente de correlación entre los resultados de ambos sistemas (Tabla 8) nos indica que éste es tendente a ser negativo y de valor muy bajo, por lo que podemos afirmar que al final del periodo no existe correlación entre ambos sistemas de evaluación.

Tabla 8

Coeficientes de correlación de los resultados de los índices EIRIS-A4

\begin{tabular}{|l|c|c|c|c|}
\hline Año & $\mathbf{2 0 0 9}$ & $\mathbf{2 0 0 8}$ & $\mathbf{2 0 0 7}$ & $\mathbf{2 0 0 6}$ \\
\hline Coeficiente de correlación EIRIS-A4 & $-0,0713$ & $-0,2230$ & $-0,3390$ & $-0,4043$ \\
\hline
\end{tabular}

Fuente: Elaboración propia.

Este fenómeno se explica por el hecho de que los indicadores que contiene el sistema EIRIS tienen un gran componente de evaluación del riesgo potencial, mientras que los incluidos en el de Asset 4 priman la evaluación de la gestión de los riesgos. Por ello, con este segundo sistema estudiado los bancos más grandes no muestran desventajas en cuanto a sus pares, sino al contrario, pues son entidades con más recorrido general en la gestión de riesgos. Aunque no resulta demasiado consistente, puede intuirse una cierta correlación positiva entre 2006 y 2008 respecto a un mayor tamaño de la empresa y mayor desarrollo de su responsabilidad sobre clientes, productos y servicios. A partir de 2009 esta correlación va perdiendo representatividad a la vez que crecen las controversias, que tienden a concentrarse en las entidades grandes y con mayor cariz de banca de inversión.

Observamos amplia movilidad de las empresas en cuanto a su posición en el ranking a lo largo del periodo analizado, con una tendencia de crecimiento constante de la calificación media entre 2006 y 2009, y una caída brusca en el año 2010. Se ha realizado un análisis por indicadores para establecer las causas de estas dinámicas y se pueden definir tres tendencias durante el periodo estudiado:

Una tendencia de mejora moderada en la implementación de políticas y sistemas de innovación y responsabilidad del producto, así como de diálogo con los clientes. Es una tendencia constante durante todo el periodo.

Sin embargo, los indicadores que hacen referencia al desempeño, es decir, a resultados concretos sobre dichos aspectos (por ejemplo: Responsabilidad del producto / Mejoras), evolucionan más irregularmente, con avances y retrocesos que en conjunto ofrecen una imagen de fin de periodo similar a la del inicio.

Finalmente los indicadores sobre controversias empeoran, especialmente a partir del año 2010, al crecer ampliamente el número de empresas que se ven sancionadas o involucradas en controversias sobre su ámbito de negocio. Por ejemplo, el indicador Responsabilidad del producto/ Controversias de consumi- 
dores, que valora si una empresa está siendo públicamente denunciada a causa de sus productos o servicios, aumenta de 0 empresas en 2006 a 9 en 2009, y a 23 entidades en 2010.

Sí se observa una correlación intensa ( $>0,75$, durante todos los años) entre la calificación obtenida en nuestro índice y el índice ESGC propuesto por Asset4, que mide la salud extra-financiera de las empresas de forma equilibrada a través de indicadores económicos, sociales, ambientales y de buen gobierno, e incluye todos los factores de controversia. Podemos afirmar que el comportamiento en términos de responsabilidad comercial o externa, es decir, sobre sus clientes, productos y servicios, se encuentra influenciado por la visión y el posicionamiento de la entidad bancaria en buen gobierno y RSC general.

\section{CONCLUSIONES}

\subsection{Conclusiones sobre los riesgos e impactos ligados a la responsabilidad social comercial de la banca y las herramientas de evaluación}

La definición de la responsabilidad social comercial o externa del sector bancario no suele relacionarse con sus propias responsabilidades primarias o técnico-financieras, pese a mantener estrechos vínculos con éstas.

Tanto la información de RSC que ofrecen los bancos como la que recogen las agencias de sostenibilidad responde a modelos estandarizados, sin reflejar siempre los riesgos y aspectos propios del sector. Además, la cierta rigidez de estas herramientas hace que sean lentas a la hora de establecer indicadores de medición tras la identificación de nuevos riesgos sociales y ambientales. Así su cobertura de los intensos impactos detectados en el ámbito de la actividad comercial de la banca durante el periodo de crisis financiera se muestra limitada, por lo que se ha realizado una propuesta de mejora.

Sería deseable la existencia de un modelo específico de medición del comportamiento en responsabilidad social comercial de la banca, y una agencia de rating especializada en ello. El impacto social y ambiental de la banca, indirecto por producirse a través de la financiación de terceros, resulta de incuestionable relevancia teniendo en cuenta que desde el sector financiero se decide si se financia o no la sostenibilidad en otros sectores. Sin embargo este hecho no queda completamente patente entre la información recogida por las agencias de calificación social.

\subsection{Conclusiones sobre el análisis de datos de la banca europea}

El trabajo con la información de dos agencias de rating en sostenibilidad de reconocido prestigio ha mostrado que la cobertura máxima conjunta de ambas herramientas sobre el modelo revisado propuesto es limitada (50\%). Se estima 
que por separado cada una de estas herramientas nos permite medir aproximadamente un tercio del modelo propuesto.

Tras el análisis de 50 entidades bancarias europeas, podemos decir que el comportamiento en términos de responsabilidad comercial o externa, es decir, sobre sus clientes, productos y servicios, se encuentra influenciado por la visión general y el posicionamiento de la entidad bancaria en RSC, incluyendo sus prácticas de responsabilidad interna y de buen gobierno.

El sector bancario muestra mayores avances en el desarrollo de políticas relacionadas con su responsabilidad social comercial, pero la implementación de estas políticas, la obtención de resultados y la transparencia son cuestiones que deben mejorar. Además, a finales del periodo estudiado el sector ha debido afrontar un aumento muy notable de sanciones y controversias sobre su ámbito de negocio, en muchos casos sobre actuaciones desarrolladas en todavía los 'años dorados' del sector.

Como balance del análisis, parece definirse una dualidad dentro del sector bancario europeo, cada vez más marcada: entidades de envergadura menor, con orientación principal a los servicios básicos de ahorro y préstamo del mercado minorista, y que consiguen realizar avances sostenidos en términos de responsabilidad social comercial; y entidades grandes, con un cierto desarrollo de políticas y sistemas de gestión en cuanto al cuidado del cliente y la innovación y calidad del producto, pero que enfrentan excesivos riesgos en el ámbito ambiental, de derechos humanos y de corrupción, que lastran su comportamiento y evolución en términos de responsabilidad social comercial. Actualmente, con los sectores tradicionales de banca social (cajas de ahorro y cooperativas de crédito) en desaparición o cuestionamiento, resulta de especial relevancia redefinir qué es banca socialmente responsable en su ámbito de negocio.

\section{REFERENCIAS BIBLIOGRÁFICAS}

BABECKÝ J., HAVRÁNEK T., MATĚJŮ J., RUSNÁK M., ŠMÍDKOVÁ K., y VAŠIČEK B. (2012): "Banking, debt, and currency crises early warning indicators for developed countries" en European Central Bank Working Paper Series, n¹485, octubre 2012.

BANCO DE ESPAÑA (2012) (a): "Informe Anual 2011". Disponible en http://www.bde.es/f/webbde/SES/Secciones/Publicaciones/PublicacionesAnuales/ InformesAnuales/11/Fich/inf2011.pdf [Último acceso: 8/04/2014].

BANCO DE ESPAÑA (2012) (b): "Encuesta del BCE sobre el acceso de las pymes a la financiación". Boletín económico: 73-80, abril 2012.

BANCO MUNDIAL (2011): "Comunicado de prensa No:2011/333/PREM. WASHINGTON D.C., 15 de febrero de 2011". Disponible en http://web.worldbank.org/WBSITE/ EXTERNAL/BANCOMUNDIAL/NEWSSPANISH/0,,contentMDK:22834036 pagePK: 64257043 piPK:437376 theSitePK:1074568,00.html [Último acceso: 13/03/2014]. 
CID GÓMEZ, JUAN MIGUEL DEL (2009): “La prevención del blanqueo de capitales: una aproximación en el contexto de la UE" en $A R I N^{\circ} 103 / 2009$. Real Instituto Elcano.

COLAU, A. y ALEMANY, A. (2013): "2007 - 2012: Retrospectiva sobre Desahucios y Ejecuciones Hipotecarias en España, Estadísticas Oficiales e Indicadores". Enero

2013. Plataforma de Afectados por la Hipoteca. Disponible en http://afectadosporlahipoteca.com/wpcontent/uploads/2013/02/RETROSPECTIVA-SOBRE-DESAHUCIOS-Y-

EJECUCIONES-HIPOTECARIAS-EN-ESPA\%C3\%91A-COLAUALEMANY1.pdf [Último acceso: 13/03/2014].

COMISIÓN DE SEGUIMIENTO DE INSTRUMENTOS HÍBRIDOS DE CAPITAL Y DEUDA SUBORDINADA (2013): "Informe sobre la comercialización de Instrumentos Híbridos de Capital y Deuda Subordinada (Real Decreto-Ley 6/2013, de 22 de Marzo)". 21 de mayo de 2013. Disponible en: http://cd00.epimg.net/descargables/ 2013/05/29/b4cf25f282b2f296123a5b81025b0653.pdf. [Último acceso: 13/03/2014].

CUESTA, M. DE LA; MUÑOZ-TORRES M.J. Y FERNÁNDEZ-IZQUIERDO, M.A. (2006): "Analysis of Social Performance in the Spanish Financial Industry Through Public Data. A Proposal" en Journal of Business Ethics, 69:289-304.

DE SERRES, A. y ROUX, M. (2006): "Les stratégies de responsabilité sociale dans les banques: comment contribuer à renforcer la cohèsion sociale à travers les activités de la finance" en Gestion; volumen 31, $n^{\circ} 2$; Verano 2006:101 y ss.

DEFENSOR DEL PUEBLO (2012): "Crisis económica y deudores hipotecarios: actuaciones y propuestas del Defensor del Pueblo". Disponible en http://www.defensordelpueblo.es/es/Documentacion/Publicaciones/monografico/ Documentacion/informe_deudores_hipotecarios.pdf [Último acceso: 8/04/2014].

DEMBINSKI, P.H.; BONVIN, J.M.; DOMMEN, E.; MONNET, F.M. (2003): "The Ethical Foundation of Responsible Investment" en Journal of Business Ethics 48: 203-213.

DOWELL-JONES, M. y KINLEY D. (2011): "The Monster Under the Bed: Financial Services and the Ruggie Framework. The UN Guiding Principles on Business and Human Rights: Foundations and Implementation" en R. Mares (ed), Brill: The Netherlands: 193-216, 2012.

ELLMERS, B. y TODOULOS, K (2013): "The UNCTAD principles on promoting responsible sovereign lending and borrowing", Eurodad (the European Network on Debt and Development), Mayo 2013. Disponible en http://www.eurodad.org/files/integration/ 2013/05/UNCTAD-Eurodad-principles-briefing.pdf [Último acceso: 8/04/2014].

FERNÁNDEZ OLIT, B. (2012): "Financial inclusion in Spain: a comparative study among Banks, Savings Banks and Cooperative Banks" en Perspectives $\mathrm{n}^{\circ} 65$. European Savings Banks Group. Octubre 2012.

FERNÁNDEZ OLIT, B. (coord.) (2008): Cómo fomentar la Inversión socialmente responsable en España. Madrid, Fundación Economistas sin Fronteras y UNED (eds.), Serie Varia.

FERNÁNDEZ OLIT, B.; PARDO, E. y CUESTA (DE LA), M. (2014): "Principales riesgos sociales y ambientales del negocio bancario en tiempos de crisis". Cuadernos Red de Cátedras Telefónica. Economistas sin Fronteras y Cátedra Telefónica-UNED de Responsabilidad Corporativa y Sostenibilidad, enero 2014. Disponible en www.responsabilidad-corporativa.es [Último acceso: 8/04/2014].

GLOBAL REPORTING INITIATIVE (2011): "Sustainability Reporting Guidelines \& Financial Services Sector Supplement. Version 3.0/FSSS Final Version”. Disponible 
en: https://www.globalreporting.org/resourcelibrary/FSSS-Complete.pdf [Último acceso: 8/04/2014].

HENDERSON, B.; PEARSON, N. y WANG, L. (2012): "New Evidence on the Financialization of Commodity Markets". Noviembre 2012. Social Science Research Network. Disponible en: http://papers.ssrn.com/sol3/papers.cfm?abstract_id=1990828 [Último acceso: 13/03/2014].

HUMPHREYS, M y BROWN A.D. (2008): "An Analysis of Corporate Social Responsibility at Credit Line: A Narrative Approach" en Journal of Business Ethics 80:403-418.

KPMG (2011): "Estudio Global sobre Blanqueo de Capitales 2011. Medidas y prácticas adoptadas por la banca en todo el mundo". Disponible en www.kpmg.es [Último acceso: 13/03/2014].

LLEWELLYN, D. T. (2009): "The new banking and financial system"; en Torrero Mañas, A. (2009): "El futuro del Sistema Financiero español (cap.)" en El futuro de la economía española: 193-202. CAJAMAR Caja Rural, Almería, Diciembre 2009.

PÉREZ-RUIZ A. y RODRÍGUEZ-DEL BOSQUE, I. (2012): "La imagen de responsabilidad social corporativa en un contexto de crisis económica: El caso del sector financiero en España" en Universia Business Review, Primer trimestre 2012: 14-29.

PRIOR F. Y ARGANDOÑA A. (2009): "Best Practices in Credit Accessibility and Corporate Social Responsibility in Financial Institutions" en Journal of Business Ethics, $n^{\circ}$ 87: 251-265.

RIBANDO, J.M. Y BONNE G. (2010): "A New Quality Factor: Finding Alpha with ASSET4 ESG Data" Starmine research note. 31 de marzo de 2010. Disponible en http://thomsonreuters.com/products/financial-risk/content/07_008/starmine-quantresearch-note-on-asset4-data.pdf [Último acceso: 10/04/2014].

ROOS, B.; OOSTERWIJK S.; SUIJS, S. y VANDENBROUCKE E. (2012): "Worldwide Investments in Cluster Munitions: A shared responsibility", Utrech, IKV Pax Christi y FairFin, junio 2012. Disponible en http://www.stopexplosiveinvestments.org/uploads/ pdf $/ 5 . \% 20$ Worldwide\%20investments $\% 20$ in $\% 20$ cluster\%20munitions; $\% 20$ a\%20shar ed\%20responsibility\%20June\%202012.pdf [Último acceso: 13/03/2014].

NACIONES UNIDAS (2011): "Principios Rectores sobre las empresas y los derechos humanos: puesta en práctica del marco de las Naciones Unidas para 'proteger, respetar y remediar"'. HR/PUB/11/04. Disponible en: http://www.ohchr.org/Documents/ Publications/GuidingPrinciplesBusinessHR_SP.pdf [Último acceso: 8/04/2014].

SCHMID-SCHÖNBEIN, O.; BRAUNSCHWEIG, A. y OETTERLI, G. (2002): "SPI-Finance 2002. Social Performance Indicators for the Financial Industry". The Project Group SPI-Finance 2002 y E2 Management Consulting Inc., Zurich. Diciembre 2002. Disponible en http://www3.uji.es/ munoz/SPI_Finance_2002.pdf [Último acceso: 8/04/2014].

SCHOLTENS, BERT (2009): "Corporate Social Responsibility in the International Banking Industry" en Journal of Business Ethics 86:159-175.

SETEM (2012): "Inversiones que son la bomba. Negocios de la banca con empresas españolas de armamento". Setem y Centro Delàs de estudios por la Paz (Justícia i Pau), 2012. Disponible en www.bancalimpia.com [Último acceso: 13/03/2014].

UNCTAD (2012): "Principles on Promoting Responsible Sovereign Lending and Borrowing" Enero 2012. Naciones Unidas. Disponible en: http://unctad.org/meetings/en/ Miscellaneous\%20Documents/Principles_Sovereign.pdf [Último acceso: 8/04/2014]. 
WORLD RESOURCES INSTITUTE Y WORLD BUSINESS COUNCIL FOR SUSTAINABLE DEVELOPMENT (2011): "Greenhouse Gas Protocol, Corporate Value Chain (Scope 3) Accounting, and Reporting Standard". Disponible en http://www.ghgprotocol.org/ [Último acceso: 8/04/2014].

WUA, M-W.; SHEN, C-H. (2013): "Corporate social responsibility in the banking industry: Motives and financial performance" en Journal of Banking \& Finance, 37: 3529-3547. 
